\title{
HOW “SAFE” SHOULD LIBRARIES BE?
}

\author{
by Brian Sturm
}

\begin{abstract}
One of the reasons I love using both public and academic libraries is that I feel safe in them. I don't just mean safe from bodily harm; I mean safe to pursue my thoughts wherever they lead me.... Within the privileged, quasi-sacred space of a library, users and the library staff who serve them have traditionally felt free to think, imagine, question, dream, and debate to their minds' as well as their hearts' content. (Isaacson, 2004)
\end{abstract}

$e$

ontemporary American society seems fraught with concern over our lack of "safety" - whether in the form of national security (USA PATRIOT Act, fighting terrorism internally and abroad, building the nation's economic underpinnings, etc.) or individual security (identity theft, Child Internet Protection Act, criminal background checks available online, etc.). We are both fascinated and frightened by the growing global community and the global information infrastructure, and we are struggling to find our place in it: individually, socially, ethically, and legally. Safety has turned from an American assumption into the consuming American question, and this change is transforming our culture, for good and for ill.

The discussion has had a direct impact on libraries, as safety in libraries becomes an increasingly relevant question. Whether it is the safety of library records, the "safety" of the content of collections, the safety of our physical bodies in library buildings, we encounter this question in multiple ways on a daily basis. We often display "safe zone" signs in our windows, proclaiming that patrons, particularly children, should consider the library building a physical retreat or haven. I firmly believe we should strive to provide this kind of safe space for all of our users.

It is vital, however, that we approach the word "safety" with due caution, and that we don't apply it to all aspects of library service. We must be careful because the words we use define us, and sometimes they imply things that we do not want to convey. "Safety" is just such a word. There are at least three levels or "types" of safety we need to consider: physical, emotional, and intellectual.

As I mentioned above, physical safety is a necessity. We need our patrons to feel physically secure in our buildings and with our staffs, so that they may move beyond that most basic of human needs. According to Abraham Maslow's hierarchy of needs, people must satisfy the more basic, survival needs such as safety and trust in order to move on to the higher ones of aesthetic appreciation and self-actualization. Without this sense of well-being, people cannot spend the time on the more ephemeral and aesthetic issues in life.

Emotional safety is also important, at least initially. People who feel emotionally threatened in our libraries will never open up to the full potential we offer. Emotional vulnerability is part of the process of intellectual risk; if patrons do not have the ego strength to stretch beyond their known limits, it is much more difficult - if not impossible - to grow intellectually. We must be safe, but we must also feel safe. Isaacson's perceptions, above, are pertinent here. It is from this feeling of safety that we are able to make the leap into the unknown, to risk becoming rather than being.

It is the third kind of safety - intellectual - that we must treat most carefully. Herein lies the crux of librarianship as a profession, and it is the cause of ongoing discussion among those in practice as they try to balance the desires of the community ("give them what they want") 
and the philosophy of the profession ("give them what will challenge them"). I believe we should NOT desire intellectual safety for our libraries because doing so undercuts the library as a fundamental democratic institution, and it defines us as purveyors of complacency. Libraries need to be intellectually incendiary institutions (see David Carr's work on museums) built on a foundation of emotional security. Vygotsky's (1978) "zone of proximal development" concept - that learners can be pushed to explore the unknown comfortably if someone with greater knowledge is nearby to help and scaffold their learning - describes precisely this kind of reaching out under the guidance (safety) of an expert. This creates an environment of intellectual seeking/challenge in an atmosphere of comfort that leads, in the best of all circumstances, to a limited loss of emotional safety, and this is where true growth can occur. It is when intellectual challenge pushes us out of our emotional comfort zone that we begin to examine not only our ideas but our fundamental beliefs. At the moment when intellect and emotion become slightly unstable, we are pushed into a liminal space, a place of uncertainty, a "fructile chaos... a storehouse of possibilities" from which we can emerge with new insight and understanding. (Turner, 1990: 11-12) "Scholars of liminality contend that much of the significant imaginative work of every society is expressed through its liminal institutions. By allowing people to escape from the rigidity of social structures and the rules of daily existence, liminality gives them the freedom to invent new solutions to old problems, or to regard familiar things in new ways." (Carnes, 2004) It is both our privilege and our responsibility to ensure that our libraries give patrons this discomfort to grow.

Come to the Edge

Come to the edge.

We might fall.

Come to the edge.

It's too high!

COME TO THE EDGE!

And they came,

and he pushed,

And they flew!

-Christopher Logue

\section{References}

Mark C. Carnes, “The Liminal Classroom,” The Chronicle of Higher Education 51 (2004): B7.

David Carr, The Promise of Cultural Institutions (Walnut Creek, Ca: Rowman and Littlefield, 2003).

David Isaacson, "Sanctuary in Libraries," American Libraries (2004): 27.

Christopher Logue, "Come to the edge." in Selected Poems, (Boston: Faber \& Faber, 1969), 64.

Abraham Maslow, Motivation and Personality (New York: Harper, 1954).

Victor Turner, "Are There Universals of Performance in Myth, Ritual, and Drama?" in By Means of Performance, ed. R. Schechner and W.

Appel, (Cambridge: Cambridge University Press, 1990), 1-18.

Lev S. Vygotsky, Mind in Society (Cambridge, MA: Harvard University Press, 1978). 